\title{
The Fertility Indicator Equation Using Serum Progesterone and Urinary Pregnanediol-3-Glucuronide for Assessment of Ovulatory to Luteal Phase Transition
}

\author{
Stephen J. Usala ${ }^{1, * \mathbb{D}}$, María Elena Alliende ${ }^{2}$ and A. Alexandre Trindade ${ }^{3}$ \\ 1 Department of Internal Medicine, Texas Tech University Health Sciences Center, 1400 S. Coulter Street, \\ Amarillo, TX 79106, USA \\ 2 Programa de Cuidado y Estudio de la Fertilidad (PROCEF), Departamento de Obstetricia, \\ Ginecología y Biología de la, Reproducción, Universidad de los Andes, Monseñor Alvaro del Portillo 12455, \\ Santiago 7620001, Chile; melenalliende@gmail.com \\ 3 Department of Mathematics and Statistics, Texas Tech University, 1108 Memorial Circle, \\ Lubbock, TX 79409, USA; alex.trindade@ttu.edu \\ * Correspondence: stephenusala@gmail.com; Tel.: +1-806-414-9145
}

Citation: Usala, S.J.; Alliende, M.E.; Trindade, A.A. The Fertility Indicator Equation Using Serum Progesterone and Urinary Pregnanediol-3-

Glucuronide for Assessment of Ovulatory to Luteal Phase Transition. Medicina 2021, 57, 134. https:// doi.org/10.3390/medicina57020134

Academic Editor:

Masafumi Koshiyama

Received: 7 January 2021

Accepted: 31 January 2021

Published: 3 February 2021

Publisher's Note: MDPI stays neutral with regard to jurisdictional claims in published maps and institutional affiliations.

Copyright: (c) 2021 by the authors. Licensee MDPI, Basel, Switzerland. This article is an open access article distributed under the terms and conditions of the Creative Commons Attribution (CC BY) license (https:/ / creativecommons.org/licenses/by/ $4.0 /)$.

\begin{abstract}
Background and Objectives: The Fertility Indicator Equation (FIE) has been shown to signal the fertile phase during the ovulatory menstrual cycle. It was hypothesized that this formulation, a product of two sequential normalized changes with a sign indicating direction of change, could be used to identify the transition from ovulatory to luteal phase with daily serum progesterone $(\mathrm{P})$ and urinary pregnanediol-3-glucuronide (PDG) levels. Materials and Methods: Day-specific serum P levels from two different laboratories and day-specific urinary PDG levels from an additional two different laboratories were submitted for FIE analysis. These day-specific levels included mean or median, 5th, 10th, 90th and 95th percentile data. They were indexed to the day of ovulation, day 0 , by ultrasonography, serum or urinary luteinizing hormone (LH). Results: All data sets showed a clear "cluster" - a periovulatory sequence of positive FIE values with a maximum. All clusters of +FIE signaled the transition from the ovulatory to luteal phase and were at least four days in length. The start day for the serum P and urinary PDG FIE clusters ranged from -3 to -1 and -3 to +2 , respectively. The end day for serum P and PDG clusters went from +2 to +7 and +4 to +8 , respectively. Outside these periovulatory FIE-P and FIE-PDG clusters, there were no consecutive positive FIE values. In addition, the maximum FIE-P and FIE-PDG values throughout the entire cycles were found in the clusters. Conclusions: FIE analysis with either daily serum P or urinary PDG levels provided a distinctive signature to recognize the periovulatory interval. The Fertility Indicator Equation served to robustly signal the transition from the ovulatory phase to the luteal phase. This may have applications in natural family planning especially with the recent emergence of home PDG tests.
\end{abstract}

Keywords: progesterone; pregnanediol-3-glucuronide; PDG; natural family planning; fertility awareness methods

\section{Introduction}

For decades, a serum progesterone(P) level has been an important part in assessing ovulatory function and the luteal phase [1] A single serum $\mathrm{P}$ of $\geq 3 \mathrm{ng} / \mathrm{mL}(9.54 \mathrm{nmol} / \mathrm{L})$ has been used as an indicator of post-ovulation [2] although recent work has set a more reliable P level to confirm ovulation at $5 \mathrm{ng} / \mathrm{mL}(15.9 \mathrm{nmol} / \mathrm{L})$ [3]. Serum P levels are usually $<1.5 \mathrm{ng} / \mathrm{mL}(4.77 \mathrm{nmol} / \mathrm{L})$ during the follicular phase and begin to increase just before the luteinizing hormone $(\mathrm{LH})$ surge $[4,5]$. After ovulation, there is a rapid increase in P. Minimum $p$ values to confirm ovulation and luteinization have been variously cited at $1.8-5.0 \mathrm{ng} / \mathrm{mL}(5.72-15.90 \mathrm{nmol} / \mathrm{L})$, [6]. Although concordance between fingerstick and 
venipuncture $\mathrm{P}$ levels has been demonstrated $[7,8]$, no point-of-care(POC) test for blood $\mathrm{P}$ measurement is presently available.

There is a renewed interest in POC progesterone-based assessment of post-ovulation with the development of urine assays for the progesterone major metabolite, pregnanediol3-glucuronide (PDG) [9-16]. Not only would a POC PDG home test aid in evaluation of fertility status, but it could also serve as an important adjunct for Natural Family Planning (NFP)/Fertility Assessment-Based Methods (FAMs) [15,16]. A role for a urinary PDG test for NFP/FAM would be to objectively signal the infertile "safe" interval and reduce the days of abstinence $[14,15]$. A test strip is available for urinary PDG measurement (Ovulation Double Check ${ }^{\mathrm{TM}}$, MFB Fertility, Boulder, CO, USA), but the signaling is based upon a threshold concept; there are $5 \mu \mathrm{g} / \mathrm{mL}(15.6 \mu \mathrm{mol} / \mathrm{L})$ and $7 \mu \mathrm{g} / \mathrm{mL}(21.8 \mu \mathrm{mol} / \mathrm{L})$ test strips $[15,16]$. With a PDG strip based upon this threshold algorithm, there were limitations to the sensitivity of detection during the post-ovulatory phase $(82-88 \%)[15,16]$. There was questionable reduction in the days of abstinence using the threshold method. With the $5 \mu \mathrm{g} / \mathrm{mL}(15.6 \mu \mathrm{mol} / \mathrm{L})$ strip for Bouchard et al. [15], the most frequent positive test was on days 4 and 5 following the LH surge, and for Leiva et al. [16], when at least one positive PDG result was obtained, the average number of luteal days was 8.8. Importantly, $50 \%$ of the participants in one study had difficulty interpreting the PDG strips by inspection alone [16].

It was hypothesized that analysis based upon a rate-of-change function using daily PDG levels might better signal the transition from the ovulatory to luteal phase. To this end, the Fertility Indicator Equation (FIE) was employed [17]. The FIE function, as first developed, utilized a multiplicative normalized change in sequential daily serum estradiol levels with a sign rule based upon confidence in direction of change. This FIE application revealed a strong signal for the entry into the fertile range with daily serum estradiol levels. To test the applicability of the FIE for detection of the periovulatory transition, daily serum P (the standard for luteal phase assessment) and daily PDG levels from four different laboratories were submitted to FIE analysis: serum P from Stricker et al. [18] and Roos et al. [19] and urinary PDG from Johnson et al. [20] and Alliende et al. [14]. Indeed, the FIE analysis with serum P (FIE-P) and with urinary PDG (FIE-PDG) created sequences of positive FIE values- "clusters" - that occurred in the periovulatory interval denoting the transition to the luteal phase.

\section{Methods}

\subsection{Fertility Indicator Equation Analysis}

The FIE and its application to daily serum estradiol levels was detailed previously [17] and will be recapitulated here. Instead of daily serum estradiol levels, daily serum P or daily urinary PDG levels are substituted in the equation.

Delta function values (relative rate of change in hormone level) for day " $\mathrm{D}-1$ " and day " $\mathrm{D}$ " are first calculated as

Delta $_{\mathrm{D}-1}=((\mathrm{P}$ or PDG level on D-1 $)-(\mathrm{P}$ or PDG level on D-2) $) /(\mathrm{P}$ or PDG level on D-2 $)$.

Delta $_{\mathrm{D}}=((\mathrm{P}$ or PDG level on D $)-($ P or PDG level on D-1 $)) /(\mathrm{P}$ or PDG level on D-1 $)$.

where D-1 is day before D and D-2 is day before D-1. That is, three values of P or PDG are necessary to compute the FIE for Day, D.

The magnitude of FIE on Day D is defined as:

$$
\text { FIE (on Day D) }=\text { Delta }-1_{1} X \text { Delta }_{\mathrm{D}} \mathrm{X} 100
$$

A sign is then assigned to this magnitude of FIE based upon the signs of Delta $a_{\mathrm{D}-1}$ and Delta $a_{D}$ and the following rules:

$$
+ \text { Delta }_{\mathrm{D}-1} \mathrm{X}+\text { Delta }_{\mathrm{D}}=+ \text { FIE; }
$$




$$
- \text { Delta }_{\mathrm{D}-1} \mathrm{X}-\text { Delta }_{\mathrm{D}}=-\mathrm{FIE} ;
$$

The sign is indeterminate (ind) when

+ Delta $_{\mathrm{D}-1} \mathrm{X}-$ Delta $_{\mathrm{D}}=$ indFIE or - Delta $_{\mathrm{D}-1} \mathrm{X}+$ Delta $_{\mathrm{D}}=$ indFIE. FIE values are therefore indeterminate if they have an indeterminate sign and are labeled "ind".

\subsection{Day-Specific Serum Progesterone and Urinary Pregnanediol-3-Glucuronide Levels}

The day-specific P and PDG levels used for the FIE analysis are tabulated in the Supplementary Materials. Day-specific serum P levels were used as reported by Stricker et al. [18] and Roos et al. [19], and day-specific urinary PDG levels were used as reported by Johnson et al. [20] and provided by Alliende et al. (Supplementary Materials) [14]. These day-specific levels variously included: mean, median, 5th, 10th, 90th, 95th percentile (PCTL) levels. Neither the method to fix the day of ovulation (Day 0) nor the hormonal assays to measure P and PDG were uniform throughout these data sets. Stricker et al. used the Abbott ARCHITECT i200 $0_{\text {SR }}$ system for progesterone and LH measurements, and for the FIE analysis Day 0 was indexed to the day after the LH peak. Roos et al. used the ADVIA Centaur XP Immunoassay system for P measurements and Day 0 was indexed to the day before disappearance of the dominant follicle with ultrasound. Johnson et al. used an in-house competitive immunoassay for PDG measurements (sensitivity $0.021 \mu \mathrm{g} / \mathrm{mL}(0.065 \mu \mathrm{mol} / \mathrm{L}))$ and Day 0 was indexed with ultrasound.

The Alliende urinary PDG levels are from a secondary analysis of data from a multicentre World Health Organization (WHO) sponsored study (HRP\#87904, approved locally, 21 September 1988). Alliende et al., used in-house non-competitive radioimmunoassays (reagents and assay protocols supplied by Matched Reagents Programme of the WHO) to measure urinary LH and PDG, and Day 0 was indexed to the day after the urinary LH rise as described previously [14].

PDG units were converted as follows: PDG $\mu \mathrm{g} / \mathrm{mL}=$ PDG mg/L; PDG mg/L $\times 3.12$ $=$ PDG $\mu \mathrm{mol} / \mathrm{L}$.

\subsection{Computations and Graphics}

Computations and graphing for Figure 1 were performed with Microsoft Excel and GraphPad Prism version 9 for Windows, GraphPad software, San Diego, CA, USA (www. graphpad.com). The graph for Figure 2 was constructed using R, A Language and Environment for Statistical Computing (R Foundation for Statistical Computing), Vienna, Austria (https: / /www.R-project.org).

\section{Results}

\subsection{FIE Analysis of Day-Specific Serum Progesterone Provides a Luteal Phase Signature}

Serum progesterone data sets from two different laboratories, Stricker et al. [18] and Roos et al. [19], were submitted for FIE computation of mean or median and 5th, 10th, 90th, and 95th percentile (PCTL) day-specific P levels. The FIE values indexed to the putative day of ovulation, Day 0, are shown in Table 1. Many of the day-specific FIE values for these progesterone data (FIE-P values) were indeterminate due to fluctuating P levels; therefore, these FIE-P values appear as ind in the tables that follow. (The complete computations with FIE-P magnitudes for the indeterminate FIE-P values are provided in the Supplementary Materials.) Of note, the FIE analysis created clear clusters of uninterrupted consecutive positive FIE-P values (FIE-P clusters in bold, Table 1). These intervals of +FIE-P started as soon as Day -3 to Day -1 . The FIE-P clusters were at least four days in length, ending on luteal days Day +2 to Day +7 . Outside these periovulatory FIE-P clusters, there were no follicular phase or later luteal phase consecutive positive FIE-P values. In addition, the maximum FIE-P values were reached in these clusters. Thus, FIE analysis with daily serum progesterone levels provided a distinctive signature of increased FIE-P values during the periovulatory interval. 
Table 1. Fertility Indicator Equation (FIE) values for day-specific serum progesterone(P) levels from Stricker et al. [18] and Roos et al. [19] using mean, median, 5th,10th, 90th and 95th percentile (PCTL) levels.

\begin{tabular}{|c|c|c|c|c|c|c|}
\hline $\begin{array}{c}\text { Day of Cycle } \\
\text { (Day 0, day of ovulation) }^{a}\end{array}$ & $\begin{array}{c}\text { FIE }^{\mathbf{b}} \\
\text { Stricker } \\
\mathbf{P} \\
\text { (mean) }\end{array}$ & $\begin{array}{c}\text { FIE } \\
\text { Stricker } \\
\text { P } \\
\text { (5th PCTL) }\end{array}$ & $\begin{array}{c}\text { FIE } \\
\text { Stricker } \\
\text { P } \\
\text { (95th PCTL) }\end{array}$ & $\begin{array}{c}\text { FIE } \\
\text { Roos } \\
\mathbf{P} \\
\text { (median) }\end{array}$ & $\begin{array}{c}\text { FIE } \\
\text { Roos } \\
\text { P } \\
\text { (10th PCTL) }\end{array}$ & $\begin{array}{c}\text { FIE } \\
\text { Roos } \\
\text { P } \\
\text { (90th PCTL) }\end{array}$ \\
\hline-16 & - & - & - & - & - & - \\
\hline-15 & - & - & - & - & - & - \\
\hline-14 & -4.62 & 0 & -11.35 & -9.88 & ind & ind \\
\hline-13 & -3.85 & ind & ind & ind & ind & ind \\
\hline-12 & -1.91 & 0 & ind & 18.75 & 11.11 & ind \\
\hline-11 & ind & 0 & ind & ind & ind & 0 \\
\hline-10 & ind & 0 & ind & 0 & ind & ind \\
\hline-9 & -1.62 & 0 & ind & ind & ind & ind \\
\hline-8 & ind & 0 & ind & -1.9 & ind & 1 \\
\hline-7 & ind & 0 & -4.44 & -5.71 & 8.33 & ind \\
\hline-6 & ind & 0 & ind & ind & 0 & ind \\
\hline-5 & 0.41 & 0 & ind & 4.8 & 0 & ind \\
\hline-4 & ind & 0 & ind & ind & ind & ind \\
\hline-3 & ind & 0 & 0.65 & ind & ind & ind \\
\hline-2 & 11.43 & 0 & 8.52 & 20.51 & 16.66 & ind \\
\hline-1 & 117.18 & 93.75 & 42.69 & 29.14 & 50 & 20.59 \\
\hline 0 & 142.65 & 78.22 & 180.82 & 30.56 & 67.5 & 29.68 \\
\hline 1 & 125.65 & 89.55 & 126.74 & 59.95 & 66.72 & 57.17 \\
\hline 2 & 101.7 & 159.4 & 60.38 & 125.11 & 16.47 & 67.45 \\
\hline 3 & 30.66 & 0.49 & 31.5 & 9.75 & ind & ind \\
\hline 4 & 9.1 & 0.38 & 1.18 & 4.55 & ind & ind \\
\hline 5 & 0.25 & ind & 0.07 & ind & ind & ind \\
\hline 6 & 0.12 & ind & 0.46 & ind & ind & ind \\
\hline 7 & ind & ind & 1.42 & ind & ind & ind \\
\hline 8 & -0.24 & -0.96 & ind & ind & ind & -0.12 \\
\hline 9 & ind & -0.75 & ind & 0.02 & -0.36 & ind \\
\hline 10 & ind & -1.73 & ind & ind & -7.16 & ind \\
\hline 11 & -3.41 & -28.24 & ind & -7.02 & -3.89 & -9.48 \\
\hline 12 & -2.68 & -18.86 & ind & & & \\
\hline 13 & -4.18 & -4.62 & ind & & & \\
\hline \multicolumn{7}{|l|}{14} \\
\hline 15 & & & & & & \\
\hline 16 & & & & & & \\
\hline
\end{tabular}

a Day 0, day of ovulation, is indexed to the day after the serum LH peak for Stricker data and as detected by ultrasound for Roos data.

$\mathrm{b}$ The FIE computations using the day-specific serum progesterone levels, the FIE-P values, are described in the Methods and listed in the Supplementary Materials. Indeterminate FIE-P values due to indeterminant sign are indicated as ind. The bold highlights the clusters, the uninterrupted intervals of positive FIE-P.

\subsection{FIE Analysis of Day-Specific Urinary Pregnanediol-3-Glucuronide Displays a Similar Periovulatory Cluster}

Testing for the major metabolite of progesterone, PDG, in urine is now available in the form of home test strips [15,16]. We were therefore interested in FIE analysis with day-specific urinary PDG data to see if this could also enable signaling of the transition from the ovulatory to luteal phase. Two different data sets of day-specific PDG levels 
were used to generate FIE values (FIE-PDG values): Johnson et al. [20] and Alliende et al. (Supplementary Materials) [14]. Indeed, observable clusters-consecutive days of positive FIE-PDG-were found (FIE-PDG clusters in bold, Table 2). These clusters began on Day -3 to Day +2 and ended on Day +4 to Day +8 . The FIE-PDG clusters were $\geq 6$ days duration. Corresponding to the FIE-P clusters, the FIE-PDG maximum values occurred within the clusters, and there were no consecutive positive FIE-PDG values outside the clusters.

Table 2. Fertility Indicator Equation(FIE) values for day-specific urinary pregnanediol-3-glucuronide (PDG) levels from Johnson et al. [20] and from Alliende et al. [14] using mean, median, 5th, 10th, 90th and 95th percentile(PCTL) levels.

\begin{tabular}{|c|c|c|c|c|c|c|c|c|c|}
\hline $\begin{array}{c}\text { Day of Cycle } \\
\text { (Day 0, Day } \\
\text { of Ovulation) }^{\text {a }}\end{array}$ & $\begin{array}{c}\text { FIE } \\
\text { Johnson } \\
\text { PDG } \\
\text { (Median) }\end{array}$ & $\begin{array}{c}\text { FIE } \\
\text { Johnson } \\
\text { PDG } \\
\text { (10th PCTL) }\end{array}$ & $\begin{array}{c}\text { FIE } \\
\text { Johnson } \\
\text { PDG } \\
\text { (90th PCTL) }\end{array}$ & $\begin{array}{c}\text { FIE } \\
\text { Alliende } \\
\text { PDG } \\
\text { (Mean) }\end{array}$ & $\begin{array}{c}\text { FIE } \\
\text { Alliende } \\
\text { PDG } \\
\text { (Median) }\end{array}$ & $\begin{array}{c}\text { FIE } \\
\text { Alliende } \\
\text { PDG } \\
\text { (5th PCTL) }\end{array}$ & $\begin{array}{c}\text { FIE } \\
\text { Alliende } \\
\text { PDG } \\
\text { (95th PCTL) }\end{array}$ & $\begin{array}{c}\text { FIE } \\
\text { Alliende } \\
\text { PDG } \\
\text { (10th PCTL) }\end{array}$ & $\begin{array}{c}\text { FIE } \\
\text { Alliende } \\
\text { PDG } \\
\text { (90th PCTL) }\end{array}$ \\
\hline-16 & - & - & - & - & - & - & - & - & - \\
\hline-15 & ind & ind & ind & - & - & - & - & - & - \\
\hline-14 & ind & ind & ind & ind & ind & ind & ind & ind & ind \\
\hline-13 & -0.5 & 0 & -0.85 & ind & 1.37 & ind & ind & ind & 4.1 \\
\hline-12 & -0.86 & ind & ind & -0.23 & ind & ind & ind & -0.07 & ind \\
\hline-11 & ind & ind & ind & ind & ind & 0.23 & 0.29 & ind & ind \\
\hline-10 & ind & 0 & ind & ind & ind & ind & ind & ind & ind \\
\hline-9 & ind & ind & ind & -0.78 & -0.09 & ind & -2.58 & ind & -3.18 \\
\hline-8 & 0 & ind & ind & ind & ind & 1.47 & ind & 3.75 & ind \\
\hline-7 & ind & ind & ind & ind & ind & ind & 1.57 & ind & 0.13 \\
\hline-6 & ind & ind & ind & -0.26 & ind & ind & ind & ind & ind \\
\hline-5 & 0 & 1.78 & ind & -0.58 & ind & ind & -3.78 & ind & -1.32 \\
\hline-4 & 0 & 0 & -1.9 & ind & ind & -0.15 & ind & ind & -0.42 \\
\hline-3 & 0 & 0 & ind & 0.43 & 0.10 & ind & 1.36 & ind & ind \\
\hline-2 & 1.57 & 0 & 3.14 & 0.45 & 0.51 & 0.47 & 1.6 & ind & 1.95 \\
\hline-1 & ind & 0 & 2.16 & 2.42 & 0.76 & 29.13 & 3.14 & 21.53 & 2.91 \\
\hline 0 & ind & 4.54 & 8.88 & 7.91 & 4.87 & 4.36 & 9.28 & ind & 10.52 \\
\hline 1 & 12.65 & 2.84 & 4.15 & 4.89 & 5.02 & 1.77 & 7.37 & ind & 0.1 \\
\hline 2 & 13.54 & 3.67 & 7.57 & 15.51 & 13.73 & 13.42 & 12.37 & 57.85 & 0.24 \\
\hline 3 & 19.67 & 28.32 & 55.07 & 32.56 & 30.50 & 55.06 & 35.05 & 26.71 & 57.64 \\
\hline 4 & 19.23 & 7.22 & 18.43 & 15.79 & 22.38 & 7.64 & 31.58 & 12.3 & 4.5 \\
\hline 5 & 13.33 & 2.28 & 16.35 & 1.77 & 1.06 & & & 13.24 & 1.46 \\
\hline 6 & 1.55 & 1.14 & 6.74 & 0.48 & 0.19 & & & 0.09 & ind \\
\hline 7 & 0.19 & 3.31 & ind & 1.79 & 1.18 & & & 0.01 & ind \\
\hline 8 & ind & 8.02 & -3.79 & ind & ind & & & ind & ind \\
\hline 9 & ind & ind & ind & ind & ind & & & ind & ind \\
\hline 10 & ind & ind & ind & & ind & & & ind & ind \\
\hline 11 & -5.47 & ind & -4.1 & & -5.71 & & & -3.79 & ind \\
\hline 12 & -2.04 & ind & -5.89 & & -4.57 & & & -7.05 & ind \\
\hline 13 & -1.06 & ind & -2.18 & & -2.51 & & & -0.24 & -9.42 \\
\hline \multicolumn{10}{|l|}{14} \\
\hline \multicolumn{10}{|l|}{15} \\
\hline 16 & & & & & & & & & \\
\hline
\end{tabular}

${ }^{\text {a }}$ Day 0 indexed according to ultrasound for Johnson et al. and by LH for Alliende et al. (ref [14] and Supplementary Materials therein). The FIE computations using the day-specific urinary pregnanediol-3-glucuronide levels are described in the Methods and in the Supplementary Materials. Indeterminate FIE values due to indeterminant sign are indicated by ind. The bold highlights the clusters, the uninterrupted intervals of positive FIE.

\subsection{Characteristics and Comparison of FIE-P and FIE-PDG Clusters}

Both the serum P and urinary PDG levels with FIE analysis showed a consistent pattern or signature for the transition from the ovulatory phase to the luteal phase. The mean FIE-P and FIE-PDG values with 95\% confidence limits for the periovulatory interval, 
Day -6 to Day +6 , are displayed in Figure 1 . The start day, end day, day of maximum FIE value, and the maximum FIE value for the FIE-P and FIE-PDG clusters are summarized in Table 3. Plots of an averaging of the FIE-P and FIE-PDG values with minimum and maximum values are shown in Figure 2.

Table 3. Start and end days of the Fertility Indicator Equation(FIE) clusters, the FIE-P and FIE-PDG clusters, for Stricker and Roos day-specific serum progesterone $(\mathrm{P})$ levels and Johnson and Alliende day-specific urinary pregnanediol-3-glucuronide (PDG) levels. ${ }^{\text {a }}$

\begin{tabular}{|c|c|c|c|c|}
\hline $\begin{array}{l}\text { Data Set, Serum P or } \\
\text { Urinary PDG }\end{array}$ & $\begin{array}{c}\text { Start Day } \\
\text { of FIE-P or FIE-PDG Cluster }\end{array}$ & $\begin{array}{c}\text { End Day } \\
\text { of FIE-P or FIE-PDG Cluster }\end{array}$ & $\begin{array}{l}\text { Day of Maximum } \\
\text { FIE-P or FIE-PDG }\end{array}$ & $\begin{array}{l}\text { FIE-P or FIE-PDG } \\
\text { Max Value }\end{array}$ \\
\hline Stricker $(\mathrm{P})$ mean & -2 & 6 & 0 & 142.65 \\
\hline Stricker( P) 5th PCTL & -1 & 4 & 2 & 159.4 \\
\hline Stricker $(\mathrm{P})$ 95th PCTL & -3 & 7 & 0 & 180.82 \\
\hline Roos $(\mathrm{P})$ median & -2 & 4 & 2 & 125.11 \\
\hline Roos (P) 10th PCTL & -2 & 2 & 0 & 67.5 \\
\hline Roos (P) 90th PCTL & -1 & 2 & 2 & 67.45 \\
\hline Johnson (PDG) median & 1 & 7 & 3 & 19.67 \\
\hline Johnson (PDG) 10th PCTL & 0 & 8 & 3 & 28.32 \\
\hline Johnson (PDG) 90th PCTL & -2 & 6 & 3 & 55.07 \\
\hline Alliende (PDG) mean & -3 & 7 & 3 & 32.56 \\
\hline $\begin{array}{l}\text { Alliende (PDG) } \\
\text { median }\end{array}$ & -3 & 7 & 3 & 30.50 \\
\hline Alliende (PDG) 5th PCTL & -2 & 4 & 3 & 55.06 \\
\hline Alliende (PDG) 10th PCTL & 2 & 7 & 2 & 57.85 \\
\hline Alliende(PDG) 90th PCTL & -2 & 5 & 3 & 57.64 \\
\hline Alliende(PDG) 95th PCTL & -3 & 4 & 3 & 35.05 \\
\hline
\end{tabular}

a Stricker, Roos, Johnson, and Alliende P and PDG levels are from references (18,19,29, and 14, respectively) and tabulated in the Supplementary Materials. Complete FIE computations for these data sets-the FIE-P and FIE-PDG values—are shown in Tables 1 and 2, and Supplementary Materials.

The FIE signatures for the urinary PDG levels had excellent concordance on the day of maximum FIE value: Day +3 with $8 / 9$ data sets and Day +2 with $1 / 9$ data sets. The FIE signatures with the serum P levels had maximum FIE values on Day 0 with $3 / 6$ data sets and on Day +2 with $3 / 6$ data sets. The FIE maximum values were higher for the serum $P$ levels vs. the urinary PDG levels, but the FIE-PDG maximum values were significantly above $0, \geq 19$. For the FIE-P results, the highest value outside the clusters for an isolated day was $\sim 19$, well below the lowest FIE-P cluster maximum of 67 . Likewise, the highest FIE-PDG value for an isolated day outside the clusters was $\sim 4$, well below the lowest FIE-PDG cluster maximum of 19.

In summary, FIE analysis with either daily serum P or daily urinary PDG levels provided a strong signal for the transition from the ovulatory to luteal phase, often starting prior to or on the day of ovulation.

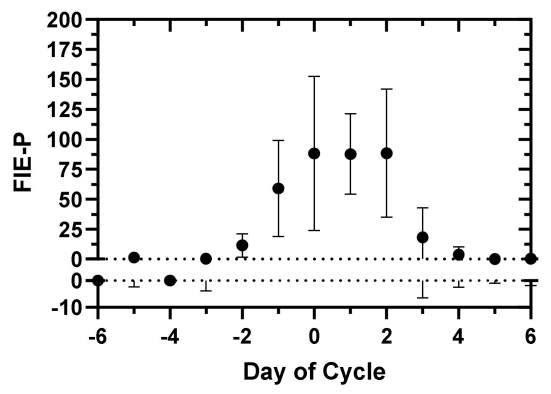

Figure 1. Cont. 


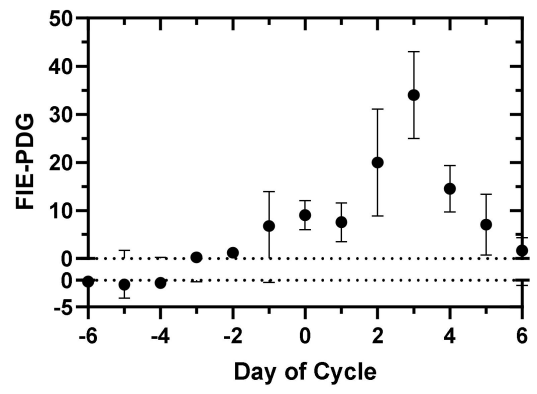

Figure 1. Mean Fertility Indicator Equation (FIE) values with $95 \%$ confidence limits for interval, Day -6 to Day +6 , using day-specific serum progesterone levels (top) and day-specific urinary pregnanediol-3-glucuronide levels (bottom) of Stricker et al. [18], Roos et al. [19], Johnson et al. [20] and Alliende et al. (Supplementary Materials and ref [14]). The FIE values, FIE-P and FIE-PDG, are listed in Tables 1 and 2. Day 0, day of ovulation.

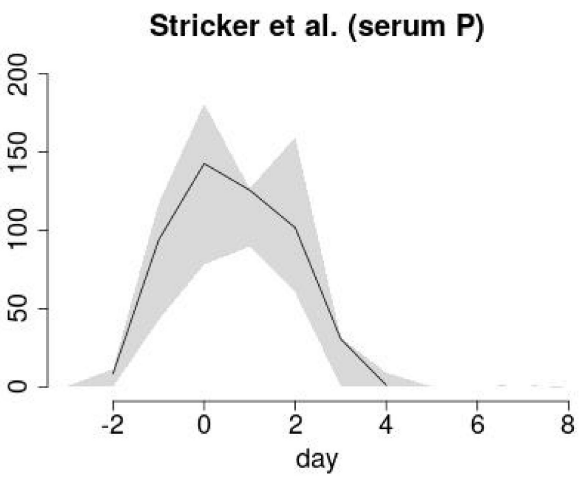

Johnson et al. (urinary PDG)

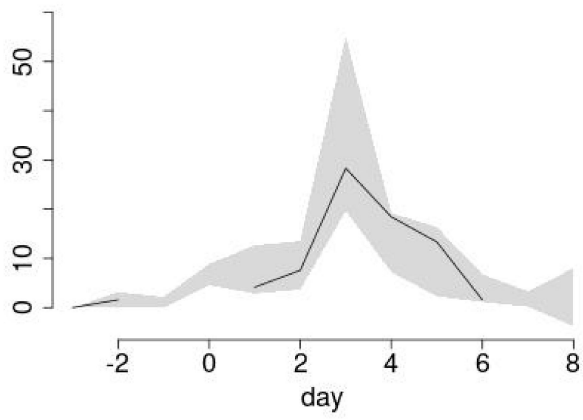

Roos et al. (serum P)

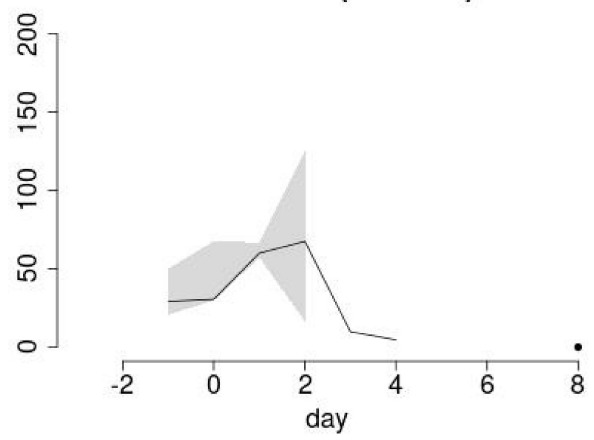

Alliende et al. (urinary PDG)

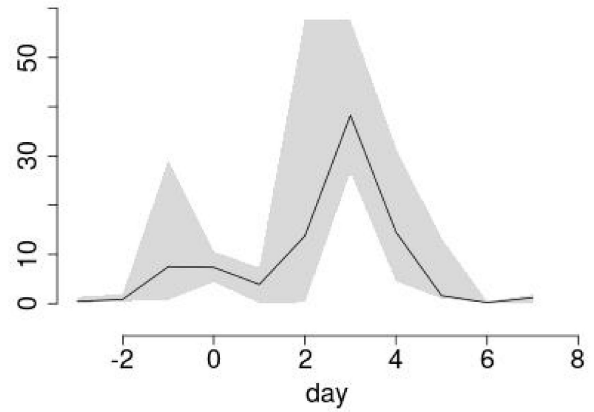

Figure 2. Plausible ranges of Fertility Indicator Equation (FIE) values from four different studies. The FIE values correspond to either day-specific serum progesterone (P) levels (top panels, Stricker et al. [18], Roos et al. [19], Table 1) or day-specific urinary pregnanediol-3-glucuronide (PDG) levels (bottom panels, Johnson et al. [20] and Alliende et al. (Supplementary Materials, [14], and Table 2)), and are plotted as a function of day of cycle (Day 0, day of ovulation). Within a particular day, individual FIE values, FIE-P or FIE-PDG, were computed from all the available data in each study: typically, a low percentile, the mean or median, and a high percentile(PCTL). The Alliende data had six data sets: mean, median, 5th, 10th, 90th, 95th PCTL, all provided in Table 2. The curves display the range of FIE values within a day, with the gray area spanning the region between the extremes (minimum and maximum). Additionally, any available values between the extremes are averaged to produce the solid line. Days with no line indicate that only two FIE values are available, whereas days with only a line signify that only one FIE value is available. Single isolated FIE values (separated by blank regions) are marked with a point (e.g., day 8 in Roos et al., top right). 


\section{Discussion}

Serum levels of the reproductive hormones, $\mathrm{LH}$, estradiol, and $\mathrm{P}$ have been used for decades to study fertility and treat infertility [21,22]. With the development of urinary $\mathrm{LH}$, and later, urinary estrone-3-glucuronide home kits, hormonal diagnostic adjuncts became available to incorporate more traditional NFP methods [23-30]. Such advances in what is now called Fertility Assessment-Based Methods(FAMs) more recently include test strips for urinary PDG, which are based upon a threshold signal of 5-7 $\mu \mathrm{g} / \mathrm{mL}$ $(15.6-21.8 \mu \mathrm{mol} / \mathrm{L})[15,16]$. However, as discussed in the introduction, there are limitations to the readability and sensitivity of these PDG strips.

Fertility Indicator Equation analysis provides an alternate way of determining the phase of the ovulatory cycle. FIE analysis is a function of relative change in hormonal levels in which the FIE magnitude includes a strict sign adjustment for directionality of the rate of change. Since there is a normalization factor in the FIE formulation, it is not expected to be so dependent on absolute hormone levels as is the case for the PDG strips and perhaps the E3G kits. Absolute levels can of course be valuable in assessing the phase of the cycle, but there is biological variability in these levels, especially estradiol and P [17], which puts constraints on the use of hormone-based FAM kits for the timing of sexual abstinence to avoid pregnancy.

Thus, FIE analysis offers a different approach. As shown previously for day-specific mean and outlier estradiol levels [17], and here with day-specific mean and median and outlier serum P and urinary PDG levels, robust signatures appear which signal the fertile and luteal phases. Indeed, even with the differences in absolute levels of P and PDG due to differences in the specifications of the assays of the four laboratories, there was an unbroken sequence of positive FIE-P and FIE-PDG values-clusters-in the periovulatory interval. Some of the variation in the start date of these sequences or clusters may be due to the differences between the studies in indexing ovulation.

The FIE-P and FIE-PDG signature raises the question: What rule would one use to determine the start day of the "safe" luteal phase, which generally occurs 1-2 days after ovulation $[29,31,32]$ ? The statistically sure answer to this question awaits FIE analysis of individual cycles and clinical application of FIE-defined algorithms. However, with the 15 FIE-P and FIE-PDG data sets here (mean, median, 5th, 10th, 90th, and 95th PCTL levels), given that the earliest start day was Day -3, and arguably assuming fertility in the 6-day interval of Day -5 to Day 0 (day of ovulation) [31,32], it is predicted that the 5th day of FIE-P or FIE-PDG rise would be the start of the infertile luteal phase. This would be the evening of Day +1 to Day +4 in 13/15 data sets and later in 2/15 data sets. Importantly, the magnitude of FIE in the cluster could also serve as a signal for the start day of the safe luteal phase. Even with some variation in the range of FIE values between the clusters, setting an FIE-PDG threshold of $\geq 19$ one finds: in the nine FIE-PDG data sets, the start day for the safe luteal phase would be Day +3 in $8 / 9$ data sets and Day +2 in $1 / 9$ data sets. Thus, both a day count of positive FIE-PDG values or an FIE-PDG threshold could be used in an algorithm to determine the safe luteal period.

The application of FIE analysis for personal use, in combination with cervical/vaginal mucus, the Marquette Method, or other NFP methods/FAMs, would require a programmed home monitor with test strips for urinary PDG levels; perhaps, even relative changes in PDG band intensities could be used given the FIE formulation. PDG test strips where band intensity reflected relative urinary concentrations would be necessary. The precise number of days for the luteal cluster of positive FIE values and possible use of a FIE threshold for such a system would need to be determined in clinical trials. The efficacy for avoiding pregnancy with such a programmed "FIE meter" would need to be tested in combination with other NFP/FAMs. 


\section{Conclusions}

Daily serum progesterone or daily urinary pregnanediol-3-glucuronide levels when submitted to Fertility Indicator Equation analysis reveal a sequence of positive FIE values that signal the transition from ovulatory to the luteal phase. The FIE signature created by serum P or urinary PDG levels can potentially be used for algorithms to improve NFP/FAMs.

Supplementary Materials: The following are available online at https:/ /www.mdpi.com/1010-6 $60 X / 57 / 2 / 134 / s 1$, Supplementary Data. Computation of values for Fertility Indicator Equation (FIE) using day-specific serum progesterone (P) levels and day-specific urinary pregnanediol-3glucuronide (PDG).

Author Contributions: Conceptualization, S.J.U.; Methodology, S.J.U., M.E.A., A.A.T.; Software, S.J.U., M.E.A., A.A.T.; Validation, S.J.U., M.E.A., A.A.T.; Formal Analysis, S.J.U., M.E.A., A.A.T.; Investigation, S.J.U., M.E.A.; Resources, S.J.U., M.E.A., A.A.T.; Data Curation, S.J.U., M.E.A.; WritingOriginal Draft Preparation, S.J.U.; Writing—Review \& Editing, S.J.U., M.E.A., A.A.T.; Visualization, S.J.U.; Supervision, S.J.U.; Project Administration, S.J.U., M.E.A.; Funding Acquisition, S.J.U., M.E.A. All authors have read and agreed to the published version of the manuscript.

Funding: This research received no external funding.

Institutional Review Board Statement: The Alliende urinary PDG levels are from a secondary analysis of data from a multicentre World Health Organization (WHO) sponsored study (HRP\#87904, approved locally, 21 September 1988).

Informed Consent Statement: Not applicable.

Data Availability Statement: Data available in Supplementary Materials.

Conflicts of Interest: The authors declare no conflict of interest.

\section{References}

1. Gabbe, S.G. Classic pages from the American Journal of Obstetrics and Gynecology. Am. J. Obstet. Gynecol. 1997, 176, 491.

2. Israel, R.; Mishell, D.R., Jr.; Stone, S.C.; Thorneycroft, I.H.; Moyer, D.L. Single luteal phase serum progesterone assay as an indicator of ovulation. Am. J. Obstet. Gynecol. 1972, 112, 1043-1046. [CrossRef]

3. Leiva, R.; Bouchard, T.; Boehringer, H.; Abulla, S.; Ecochard, R. Random serum progesterone threshold to confirm ovulation. Steroids 2015, 101, 125-129. [CrossRef] [PubMed]

4. Carmina, E.; Stanczyk, F.Z.; Lobo, R.A. Laboratory assessment. In Reproductive Endocrinology, 7th ed.; Strauss, J.F., III, Barbieri, R.L., Eds.; Elsevier Saunders: Philadelphia, PA, USA, 2013; pp. 822-851.

5. O'Connor, K.A.; Brindle, E.; Holman, D.J.; Klein, N.A.; Soules, M.R.; Campbell, K.L.; Fortune, K.; Munro, C.J.; Shofer, J.B.; Lasley, B.L.; et al. Urinary estrone conjugate and pregnanediol-3-glucuronide enzyme immunoassays for population research. Clin. Chem. 2003, 49, 1139-1148. [CrossRef]

6. Takaya, Y.; Matsubayashi, H.; Kitaya, K.; Nishiyama, R.; Yamaguchi, K.; Takeuchi, T.; Tomomoto, I. Minimum values for midluteal plasma progesterone and estradiol concentrations in patients who achieved pregnancy with timed intercourse or intrauterine insemination without a human menopausal gonadotropin. BMC Res. Notes 2018, 11, 61. [CrossRef]

7. Edelman, A.; Stouffer, R.; Zava, D.T.; Jensen, J.T. A comparison of blood spot vs. plasma analysis of gonadotropin and ovarian steroid hormone levels in reproductive-age women. Fertil. Steril. 2007, 88, 1404-1407. [CrossRef]

8. Burke, E.E.; Beqaj, S.; Douglas, N.C.; Luo, R. Concordance of Fingerstick and Venipuncture Sampling for Fertility Hormones. Obstet. Gynecol. 2019, 133, 343-348. [CrossRef]

9. Blackwell, L.F.; Cooke, D.G.; Brown, S. The Use of Estrone-3-Glucuronide and Pregnanediol-3-Glucuronide Excretion Rates to Navigate the Continuum of Ovarian Activity. Front. Public Health 2018, 6, 153-165. [CrossRef]

10. Blackwell, L.F.; Vigil, P.; Gross, B.; d'Arcangues, C.; Cooke, D.G.; Brown, J.B. Monitoring of ovarian activity by measurement of urinary excretion rates of estrone glucuronide and pregnanediol glucuronide using the Ovarian Monitor, Part II: Reliability of home testing. Hum. Reprod. 2011, 27, 550-557. [CrossRef]

11. Blackwell, L.F.; Vigil, P.; Cooke, D.G.; d'Arcangues, C.; Brown, J.B. Monitoring of ovarian activity by daily measurement of urinary excretion rates of oestrone glucuronide and pregnanediol glucuronide using the Ovarian Monitor, Part III: Variability of normal menstrual cycle profiles. Hum. Reprod. 2013, 28, 3306-3315. [CrossRef]

12. Blackwell, L.F.; Vigil, P.; Alliende, M.E.; Brown, S.; Festin, M.; Cooke, D.G. Monitoring of ovarian activity by measurement of urinary excretion rates using the Ovarian Monitor, Part IV: The relationship of the pregnanediol glucuronide threshold to basal body temperature and cervical mucus as markers for the beginning of the post-ovulatory infertile period. Hum. Reprod. 2016, 31, 445-453. [PubMed] 
13. Ecochard, R.; Leiva, R.; Bouchard, T.; Boehringer, H.; Direito, A.; Mariani, A.; Fehring, R. Use of urinary pregnanediol 3glucuronide to confirm ovulation. Steroids 2013, 78, 1035-1040. [CrossRef] [PubMed]

14. Alliende, M.E.; Arraztoa, J.A.; Guajardo, U.; Mellado, F. Towards the Clinical Evaluation of the Luteal Phase in Fertile Women: A Preliminary Study of Normative Urinary Hormone Profiles. Front. Public Health 2018, 6, 147. [CrossRef] [PubMed]

15. Bouchard, T.P.; Fehring, R.J.; Schneider, M. Pilot Evaluation of a New Urine Progesterone Test to Confirm Ovulation in Women Using a Fertility Monitor. Front. Public Health 2018, 7, 184. [CrossRef] [PubMed]

16. Leiva, R.; McNamara-Kilian, M.; Niezgoda, H.; Ecochard, R.; Bouchard, T. Pilot observational prospective cohort study on the use of a novel home-based urinary pregnanediol 3-glucuronide (PDG) test to confirm ovulation when used as adjunct to fertility awareness methods (FAMs) stage 1. BMJ Open 2018, 9, e028496. [CrossRef]

17. Usala, S.J.; Trindade, A.A. A Novel Fertility Indicator Equation Using Estradiol Levels for Assessment of Phase of the Menstrual Cycle. Medicina 2020, 56, 555. [CrossRef]

18. Stricker, R.; Eberhart, R.; Chevailler, M.C.; Quinn, F.A.; Bischof, P.; Stricker, R. Establishment of detailed reference values for luteinizing hormone, follicle stimulating hormone, estradiol, and progesterone during different phases of the menstrual cycle on the Abbott ARCHITECT analyzer. Clin. Chem. Lab. Med. 2006, 44, 883-887. [CrossRef]

19. Roos, J.; Johnson, S.; Weddell, S.; Godehardt, E.; Schiffner, J.; Freundl, G.; Gnoth, C. Monitoring the menstrual cycle: Comparison of urinary and serum reproductive hormones referenced to true ovulation. Eur. J. Contracept. Reprod. Health Care 2015, 20, 438-450. [CrossRef]

20. Johnson, S.; Weddell, S.; Godbert, S.; Freundl, G.; Roos, J.; Gnoth, C. Development of the first urinary reproductive hormone ranges referenced to independently determined ovulation day. Clin. Chem. Lab. Med. 2015, 53, 1099-1108. [CrossRef]

21. Direito, A.; Bailly, S.; Mariani, A.; Ecochard, R. Relationships between the luteinizing hormone surge and other characteristics of the menstrual cycle in normally ovulating women. Fertil. Steril. 2013, 99, 279-285. [CrossRef]

22. Ecochard, R.; Bouchard, T.; Leiva, R.; Abdulla, S.; Dupuis, O.; Duterque, O.; Garmier Billard, M.; Boehringer, H.; Genolini, C. Characterization of hormonal profiles during the luteal phase in regularly menstruating women. Fertil. Steril. 2017, 108, 175-182. [CrossRef] [PubMed]

23. Bouchard, T.P.; Genuis, S.J. Personal fertility monitors for contraception. Can. Med. Assoc. J. 2010, 183, 73-76. [CrossRef] [PubMed]

24. Fehring, R.J.; Schneider, M.; Barron, M.L. Efficacy of the Marquette Method of natural family planning. MCN Am. J. Matern. Nurs. 2008, 33, 348-354. [CrossRef] [PubMed]

25. Hilgers, T.W.; Stanford, J.B. Creighton Model NaProEducation Technology for avoiding pregnancy. Use effectiveness. J. Reprod. Med. 1998, 43, 495-502. [PubMed]

26. Blackwell, L.; Cooke, D.; Brown, S. Self-monitoring of fertility hormones: A new era for natural family planning? Linacre Q. 2018, 85, 26-34. [CrossRef] [PubMed]

27. Fehring, R.J.; Bouchard, T.; Schneider, M. Comparison of Abstinence and Coital Frequency Between Two Natural Methods of Family Planning; Marquette University: Milwaukee, WI, USA, 2013.

28. Simmons, R.G.; Jennings, V. Fertility awareness-based methods of family planning. Best Prac. Res. Clin. Obstet. Gynaecol. 2020, 66, 68-82. [CrossRef] [PubMed]

29. Freundl, G.; Godehardt, E.; Kern, P.A.; Frank-Herrmann, P.; Koubenec, H.J.; Gnoth, C. Estimated maximum failure rates of cycle monitors using daily conception probabilites in the menstrual cycle. Hum. Reprod. 2003, 18, 2628-2633. [CrossRef] [PubMed]

30. Alliende, M.E.; Cabezón, C.; Figueroa, H.; Kottmann, C. Cervicovaginal fluid changes to detect ovulation accurately. Am. J. Obstet Gynecol. 2005, 193, 71-75. [CrossRef] [PubMed]

31. Dunson, D.B.; Baird, D.D.; Wilcox, A.J.; Weinberg, C.R. Day-specific probabilities of clinical pregnancy based on two studies with imperfect measures of ovulation. Hum. Reprod. 1999, 14, 1835-1839. [CrossRef] [PubMed]

32. Stanford, J.B.; White, G.L.; Hatasaka, H. Timing intercourse to achieve pregnancy: Current evidence. Obstet Gynecol. 2002, 100, 1333-1341. [CrossRef] 